\title{
Microstructure Changes of Ti-Al-C Films Deposited by Filtered Cathodic Vacuum Arc
}

\author{
Xianjuan Pang, ${ }^{1,2,3}$ Xiaoqiang Liu, ${ }^{2}$ and Bo Jin ${ }^{2}$ \\ ${ }^{1}$ School of Chemical Engineering and Pharmaceutics, Henan University of Science and Technology, \\ No. 263 Kaiyuan Road, Luoyang 471023, China \\ ${ }^{2}$ State Key Laboratory of Solid Lubrication, Lanzhou Institute of Chemical Physics, Chinese Academy of Sciences, \\ Lanzhou 730000, China \\ ${ }^{3}$ Henan Key Laboratory of Materials Tribology, Luoyang 471003, China
}

Correspondence should be addressed to Xianjuan Pang; xjpang2001@haust.edu.cn

Received 5 March 2014; Accepted 2 April 2014; Published 24 April 2014

Academic Editor: Jinlong Jiang

Copyright (C) 2014 Xianjuan Pang et al. This is an open access article distributed under the Creative Commons Attribution License, which permits unrestricted use, distribution, and reproduction in any medium, provided the original work is properly cited.

\begin{abstract}
Nanocomposite Ti-Al-C films were deposited by filtered cathodic vacuum arc (FCVA) at different $\mathrm{CH}_{4}$ flows. The deposited films were characterized in terms of elemental and phase compositions, chemical bonds, and texture as a function of $\mathrm{CH}_{4}$ flow rate by XRD, XPS, HRTEM, Raman spectroscopy, and IR spectroscopy. The results show that the TiC grain size decreases from 4.2 to $2.9 \mathrm{~nm}$ as the $\mathrm{CH}_{4}$ flow rate increases from 30 to $80 \mathrm{sccm}$. The analysis of XPS, HRTEM, and Raman spectroscopy shows that the microstructure of deposited films turns from a TiC dominant TiC-C film to a carbon network dominant TiAl-doped a-C film structure as the $\mathrm{CH}_{4}$ flow increases from $30 \mathrm{sccm}$ to $80 \mathrm{sccm}$. IR spectroscopy shows that most of the hydrogen atoms in the deposited films are bonded to the $\mathrm{sp}^{3}$-hybridized $\mathrm{C}$ atoms. All the composition and microstructure change can be explained by considering the plasma conditions and the effect of $\mathrm{CH}_{4}$ flow.
\end{abstract}

\section{Introduction}

Advanced methods in surface technologies, providing new thin film materials with multifunctional properties, are demanded with progress in future engineering applications in tribology, machining, and manufacturing processes. For example, applications in tribology or machining of steels and alloys require coatings combining low friction coefficient, high hardness, and chemical and high temperature stability. These requirements of multifunctionality of the surface of components and/or tools could be met by applying improved coating concepts like metastable, multilayer, gradient, and nanocomposite PVD coatings [1]. In particular, nanostructured coatings, which consist of hard and solid lubricant phases, have attracted increasing interest because of the possibilities of synthesizing materials with unique mechanical and physical properties [2].

Graphite is one of typical solid lubricants of great technological interests. Carbon thin film deposition technology has reached an advanced status on its way from first laboratory results to commercially available products from soft graphitelike to hard amorphous and super hard diamond-like films. Diamond-like carbon coatings offer outstanding physicochemical properties such as relatively high hardness, chemical inertness, high wear resistance, and low friction coefficient [3]. However, there are still several problems, such as low toughness and high internal stress, which limits a-C:H films being used in a wide range of industrial applications [3-6]. Many studies have demonstrated that mono- and/or codoping some metal and nonmetal elements into a-C:H films can effectively reduce internal stress and improve mechanical and tribological properties $[1,6-8]$.

Filtered cathodic vacuum arc (FCVA) deposition is a promising technique for the production of high quality hard thin films, the main feature of which is to employ a curved magnetic field to guide the plasma generated from the cathodic vacuum arc to deposit on an out-of-sight substrate. Through this special magnetic filter, most of the unwanted macroparticles and neutral atoms will be removed. Only ions within a defined energy range can reach the substrate, thus 
TABLE 1: Summary of the films deposition conditions.

\begin{tabular}{lc}
\hline Item & Parameter \\
\hline $\mathrm{CH}_{4}$ gas flow rate $(\mathrm{sccm})$ & $30,40,50,60,70,80$ \\
Ar gas flow rate $(\mathrm{sccm})$ & 120 \\
Deposition pressure $(\mathrm{Pa})$ & $0.54 \sim 0.70$ \\
Thickness $(\mu \mathrm{m})$ & 1.5 \\
Arc current $(\mathrm{A})$ & 80 \\
\hline
\end{tabular}

producing films with good controllability and reproducibility [9-11].

In this paper, $\mathrm{Ti}-\mathrm{Al}-\mathrm{C}$ ternary nanocomposite films were deposited by FCVA, TiAl target being used as cathode at the methane and argon atmosphere. The investigations were mainly focused on the change of microstructure in the deposited films as a function of $\mathrm{CH}_{4}$ flow rate.

\section{Experiment}

The Ti-Al-C films were deposited by the FCVA technique. It employs a $90^{\circ}$ curved filter to remove the macroparticles. Titanium aluminum cylindrical composite target (TiAl (70/30 at.)) was used to generate plasma with $65 \mathrm{~mm}$ in diameter. A rotated substrate holder was placed normal to the arc plasma beam at a distance of $10 \mathrm{~cm}$ from the exit of the FCVA source. The deposition conditions are detailed in Table 1 . The vacuum chamber with $900 \mathrm{~mm}$ in diameter was evacuated to the base pressure less than $3.2 \times 10^{-3} \mathrm{~Pa}$, which was then backfilled with methane and argon at a pressure of $\sim 0.6 \mathrm{~Pa}$ for depositing the films. A Si $n(100)$ wafer was used for the substrate. Prior to deposition, the silicon substrates were sputtered by an Ar ion beam for $10 \mathrm{~min}$ at a pulsed substrate negative bias voltage of $-700 \mathrm{~V}$, to remove some adhering impurities and the native oxide layer on substrates. Subsequently, the films were deposited at a pulsed substrate negative bias voltage of $-100 \mathrm{~V}$ and varied the $\mathrm{CH}_{4}$ flow.

The microstructure and grain size are determined by $\mathrm{X}$ ray diffraction (XRD) with a Philips X'pert diffractometer operated with $\mathrm{Cu} \mathrm{Ka}$ radiation in a glancing incident configuration $\left(\theta=1^{\circ}\right)$. After ruling out influence of instrumental broadening the average grain size $(D)$ of film is calculated from the full width at half maximum (FWHM) of the TiC(111) peak using Scherrer's formula [12]:

$$
D=\frac{k \lambda}{B \cos \theta}
$$

where constant $k=0.89, B$ is the FWHM (degree), $\lambda$ is the wavelength $(\mathrm{nm})$, and $\theta$ is the diffraction angle (degree).

High-resolution transmission electron microscopy (HRTEM) investigations and selected area diffraction (SAD) were performed on a JEM 2010 transmission electron microscope operated at $200 \mathrm{kV}$. About $20 \mathrm{~nm}$ thick films were produced on single crystals of $\mathrm{NaCl}$ for HRTEM investigations. Plan-view samples were made by floating off the films in distilled water and placing them on $\mathrm{Cu}$ grids.

The chemical composition of the films was determined by X-ray photoelectron spectroscopy analysis using a PHI$5702 \mathrm{X}$-ray photoelectron spectroscope (XPS) operating with monochromatized $\mathrm{Al} \mathrm{Ka}$ radiation. After the removal of adventitious contamination corresponding to about $2 \mathrm{~nm}$ of carbon by ion sputter cleaning $\left(4 \mathrm{KeV} \mathrm{Ar}^{+}\right)$, the elemental composition was measured from the peak areas of Ti2p, $\mathrm{C} 1 s$, and Alls. Using the built-in sensitivity factors, the concentrations were determined from the respective areas. Analysis of the peak shapes using curve fitting on the Ti2 $p_{3 / 2}$ and $\mathrm{C} 1 s$ peaks with carefully chosen profiles allowed the separation of $\mathrm{TiC}$ and a-C:H phases at different methane flow for details.

Raman spectra were performed on a Horiba Jobin Yvon HR800 spectrometer at room temperature using the $532 \mathrm{~nm}$ line of an Ar laser as the excitation source. Moreover, the Raman spectra were recorded in the range of $200-2000 \mathrm{~cm}^{-1}$ and special care was taken to avoid sample damage during measurements. Fourier transformation infrared (FTIR) spectra of deposited films were recorded on an IFS 66v/s spectrometer so as to detect the changes of the hydrogen bonding in the films.

\section{Results and Discussion}

3.1. Composition. Table 2 plots the variation of the $\mathrm{Ti}, \mathrm{Al}$, and $\mathrm{C}$ atomic ratios versus the applied methane flow during the deposition. It can be found that the content of $\mathrm{Al}$ changes slightly while the Ti concentration shows a decrease from 25.32 at.\% to 11.92 at.\% with increasing $\mathrm{CH}_{4}$ flow rate from $30 \mathrm{sccm}$ to $80 \mathrm{sccm}$. This is attributed to the poisoning effect; namely, with increasing $\mathrm{CH}_{4}$ flow, the Ti cathode was poisoned and a compound layer of $\mathrm{TiC}$ was formed on the target surface. Meanwhile, Al belongs to weaker-carbideforming metal, which is relatively difficult to form Al-C on the target surface. TiC has a significantly higher melting point $\left(3150^{\circ} \mathrm{C}\right)$ comparing with the TiAl cathode (melting point of Ti $1660^{\circ} \mathrm{C}$ ), which affects the plasma emission from the arc spots, resulting in reduction in the concentration of $\mathrm{Ti}$ and the slight change of $\mathrm{Al}$ concentration in deposited films. By contrast, the carbon concentration increased with an increase in the flow rate, a clear evidence of the poisoning effect. Meanwhile, an increasing $\mathrm{CH}_{4}$ flow enhances deposition of carbon; therefore, the $\mathrm{C}$ concentration increases from 58.75 at. $\%$ to 68.80 at.\% with increasing $\mathrm{CH}_{4}$ flow from $40 \mathrm{sccm}$ to $50 \mathrm{sccm}$. After that, with $\mathrm{CH}_{4}$ flow further increasing the $\mathrm{C}$ concentration changed slightly, which is due to the balance of plasma [2].

3.2. Structure of Deposited Films. XRD experiment is performed to identify the microstructure of deposited films and the results are presented in Figure 1(a). The peak around $55^{\circ}$ is from the Si (100) substrate underneath the film. Peaks at $35.4,41.0$, and $59.6^{\circ}$ are attributed to (111), (200), and (220) diffraction planes of $\mathrm{TiC}[1,13-16]$. All these patterns exhibit relatively broad peaks.

The grain size of the nanocrystalline component is essential for the understanding of the nanostructure and hence of the properties of nanocomposite hard films. It was routinely evaluated from the XRD peak broadening taking the full width at half maximum (FWHM) of the TiC (111) peak in the Scherrer formula. The data were corrected for instrumental 


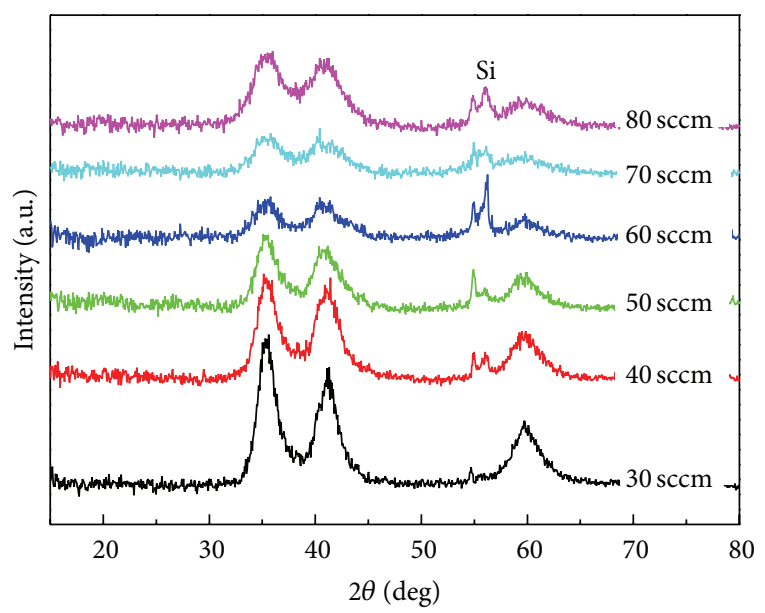

(a)

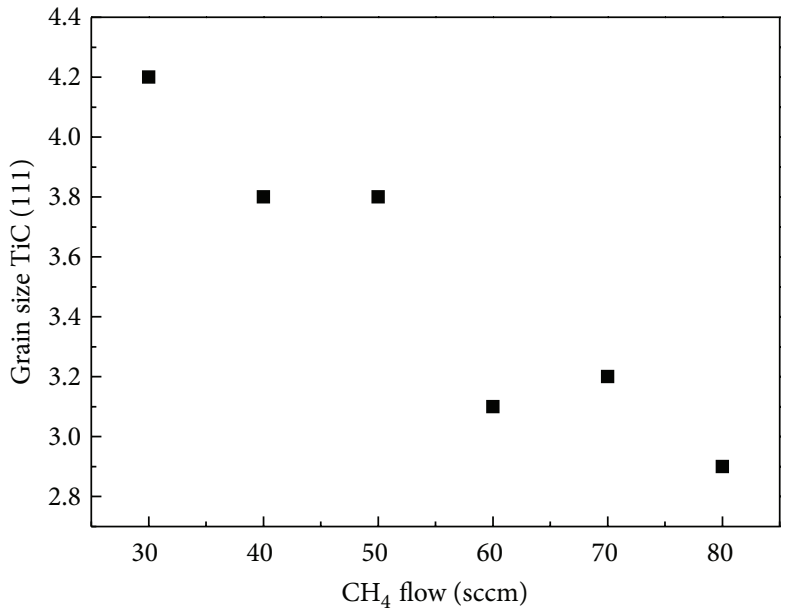

(b)

FIGURE 1: (a) The XRD spectra of the films prepared at different $\mathrm{CH}_{4}$ flow; (b) the grain size of deposited films as a function of the $\mathrm{CH}_{4}$ flow.

TABle 2: Chemical composition: $\mathrm{Ti} / \mathrm{Al}, \mathrm{Al} /(\mathrm{Ti}+\mathrm{Al})$, and $\mathrm{C} /(\mathrm{Ti}+\mathrm{Al})$ atomic concentration ratios of deposited Ti-Al-C films.

\begin{tabular}{|c|c|c|c|c|c|c|}
\hline & \multicolumn{3}{|c|}{ Elemental composition (at.\%) } & \multirow{2}{*}{$\mathrm{Ti} / \mathrm{Al}$} & \multirow{2}{*}{$\mathrm{Al} /(\mathrm{Ti}+\mathrm{Al})$} & \multirow{2}{*}{$\mathrm{C} /(\mathrm{Ti}+\mathrm{Al})$} \\
\hline & $\mathrm{Ti}$ & $\mathrm{Al}$ & $\mathrm{C}$ & & & \\
\hline $30 \mathrm{sccm}$ & 25.32 & 15.89 & 58.79 & 1.59 & 0.39 & 1.43 \\
\hline $40 \mathrm{sccm}$ & 21.95 & 19.29 & 58.75 & 1.14 & 0.47 & 1.42 \\
\hline $50 \mathrm{sccm}$ & 14.16 & 17.04 & 68.80 & 0.83 & 0.41 & 2.21 \\
\hline $60 \mathrm{sccm}$ & 14.86 & 15.83 & 69.31 & 0.94 & 0.52 & 2.26 \\
\hline $70 \mathrm{sccm}$ & 13.01 & 15.93 & 71.07 & 0.82 & 0.55 & 2.46 \\
\hline $80 \mathrm{sccm}$ & 11.92 & 17.81 & 70.26 & 0.67 & 0.58 & 2.36 \\
\hline
\end{tabular}

broadening. The evolution of the grain size with $\mathrm{CH}_{4}$ flow, obtained from this method, is displayed in Figure 1(b). It can be found that the grain size decreases from 4.2 to $2.9 \mathrm{~nm}$ as the $\mathrm{CH}_{4}$ flow rate increases from 30 to $80 \mathrm{sccm}$.

A comparison of these values with data obtained from HRTEM shows that the values obtained from XRD agree reasonably well. This is illustrated in Figure 2 showing the HRTEM and SAED micrographs of the films. Indexing the lattice fringes and also the circular selected area diffraction patterns confirms the formation of $\mathrm{TiC}$ nanocrystalline phases.

The interplanar spacing of $\mathrm{TiC}$ (311) plane is about $0.13 \mathrm{~nm}$, shown in Figure 2(a). The diffraction rings shown in Figure 2(b) are attributed to (111), (200), and (220) planes of $\mathrm{TiC}$. In Figure 2, it shows fine-grained $\mathrm{TiC}$ crystals of about $5 \mathrm{~nm}$ in the case of films deposited at $30 \mathrm{sccm}$ of $\mathrm{CH}_{4}$ flow rate and a reduced quantity and grain size smaller than $5 \mathrm{~nm}$ in the case of films deposited at $50 \mathrm{sccm}$ of $\mathrm{CH}_{4}$ flow rate. It also clearly shows, on the one hand, many small $\mathrm{TiC}$ crystallites represented by the lattice fringes of $\mathrm{TiC}$ and, on the other hand, some areas not contributing to the imaging in the electron microscope. These areas could be interpreted to be an amorphous carbon phase, as is expected from the chemical composition of the coatings. It can be inferred that nanocomposite coatings have a two-phase microstructure, built of a nanocrystalline $\mathrm{TiC}$ phase and an amorphous carbon phase. However, the microstructure of the films changes from TiC-based structure to C-based structure in which the nanocrystalline $\mathrm{TiC}$ particles are homogeneously embedded in the a-C:H matrix, as the $\mathrm{CH}_{4}$ flow rate increases from $30 \mathrm{sccm}$ to $50 \mathrm{sccm}$.

3.3. Raman Spectroscopy and XPS Analysis. The application of Raman spectroscopy enables the interpretation of the bonding in the deposited films. Figure 3 shows the Raman spectra of all the films deposited at different $\mathrm{CH}_{4}$ flows. It reveals two important facts. (1) In all measured films vibrational modes in the range of $450-750 \mathrm{~cm}^{-1}$ indicative of titanium carbide were detected [17]. (2) C-C bonds observable as a typical camel-like shape with humps at 1360 and $1590 \mathrm{~cm}^{-1}$ so-called D and G peak were detected [57]. The structural changes can also be seen as the $\mathrm{CH}_{4}$ flow increases from $30 \mathrm{sccm}$ to $80 \mathrm{sccm}$.

Further complementary information on the constitution and microstructure of these deposited films is available from XPS. The chemical states of $\mathrm{C}, \mathrm{Ti}, \mathrm{Al}$, and $\mathrm{O}$ in the deposited films are analyzed by XPS as shown in Figure 4. It can be initially referred that the $\mathrm{Cls}$ spectra show discrimination of these two components at the binding energies of 281.6 and $284.5 \mathrm{eV}$, respectively, both of which are responding to $\mathrm{TiC}$ and $\mathrm{a}-\mathrm{C}: \mathrm{H}$ phases. However, the $\mathrm{Cls}$ spectra are different. At low $\mathrm{CH}_{4}$ flow, the $\mathrm{TiC}$ phase is dominant, 


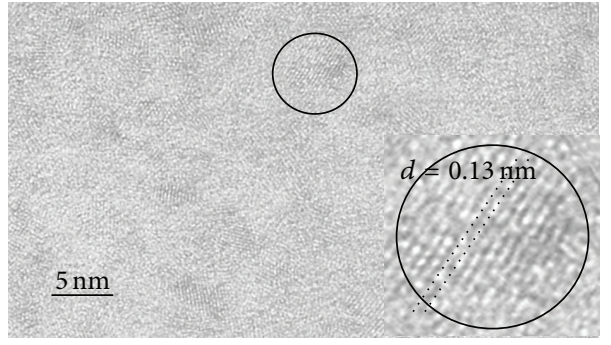

(a)

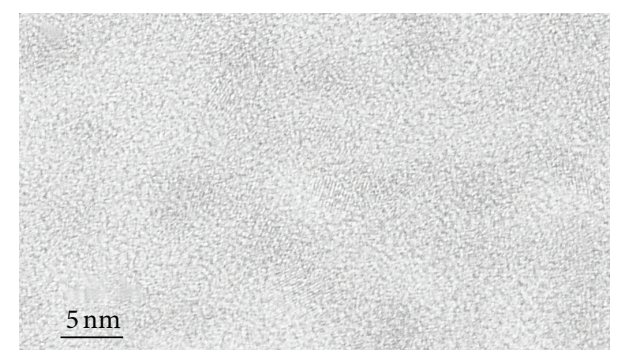

(c)

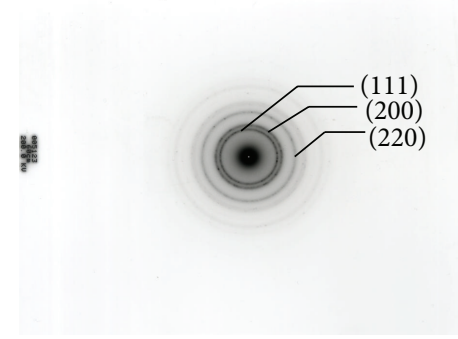

(b)

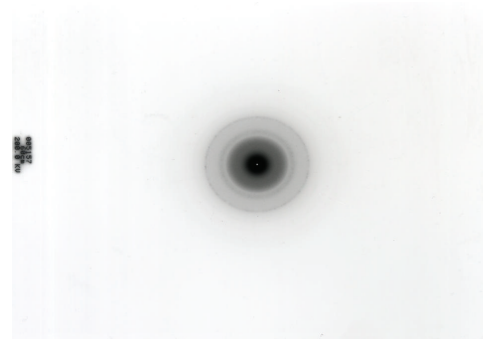

(d)

FIGURE 2: HR-TEM and SAED images of films deposited at different $\mathrm{CH}_{4}$ flow (a) and (b): $30 \mathrm{sccm}$ and (c) and (d): $50 \mathrm{sccm}$.

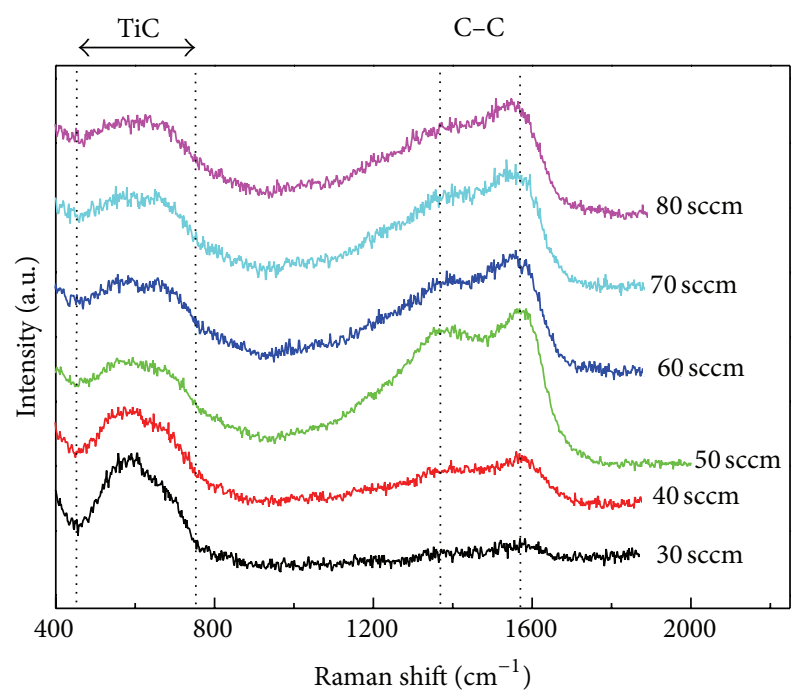

FIGURE 3: Raman spectra of the films prepared at different $\mathrm{CH}_{4}$ flow.

while the a-C:H phase changes to be dominant at higher $\mathrm{CH}_{4}$ flow, which demonstrates the structural change with increasing the $\mathrm{CH}_{4}$ flow. The same concentration profile is obtained using the Ti $2 p_{3 / 2}$ peak and performing curve-fitting procedures to separate the contributions from metallic and carbidic titanium. However, the difference in position of the carbide and metallic titanium is only $1.1 \mathrm{eV}$ and the respective binding energies are $454.9 \mathrm{eV}$ and $453.8 \mathrm{eV}$ and hence the determination is less accurate than from $\mathrm{C} 1 s$. The $\mathrm{Cls}$ peak can be fitted into five components around $281.6 \mathrm{eV}, 282.6 \mathrm{eV}$, $284.1 \pm 0.1 \mathrm{eV}, 285.0 \pm 0.1 \mathrm{eV}$, and $286.7 \pm 0.1 \mathrm{eV}$, in which the peaks at $284.1 \pm 0.1 \mathrm{eV}$ and $285.0 \pm 0.1 \mathrm{eV}$ correspond to $\mathrm{sp}^{2}$ and $\mathrm{sp}^{3} \mathrm{C}-\mathrm{C}$ bonds $[1,5-7]$, and the peak with much smaller intensity near $286.7 \pm 0.1 \mathrm{eV}$ is assigned to the $\mathrm{C} 1 \mathrm{~s}$ in the $\mathrm{C}-\mathrm{O}$ bond. The peak at around 281.6 indicates the presence of TiC, and the peak at $282.6 \mathrm{eV}$ assigned to $\mathrm{TiC}^{*}$ compared to $\mathrm{TiC}$ suggests additional carbon atoms in the vicinity of TiC $[1,18]$. This is the case for $\mathrm{C}$ knocked into $\mathrm{TiC}$ during sputtering and at the interface of $\mathrm{TiC}$ and carbon phase. Combining the results of Raman, XRD, and XPS spectrum, it proves the microstructural change of the deposited films as the $\mathrm{CH}_{4}$ flow increases from $30 \mathrm{sccm}$ to $80 \mathrm{sccm}$. The structure of films deposited at 30 and $40 \mathrm{sccm} \mathrm{CH}_{4}$ flows is TiC dominant TiC$\mathrm{C}$ film, which changes to a carbon network dominant TiAldoped a-C film as the $\mathrm{CH}_{4}$ flows up to $80 \mathrm{sccm}$.

3.4. IR Analysis. In order to get more structural details, IR spectroscopy is used in this sense to characterize the C$\mathrm{H}$ bonding in deposited hydrogenated carbonaceous films. Figure 5 shows the IR absorption spectra of the films deposited at different $\mathrm{CH}_{4}$ flows. It can be found that the $\mathrm{C}-\mathrm{H}$ absorption peaks are centered at $2920 \mathrm{~cm}^{-1}$, which is associated with the asymmetric stretching mode of the hydrogen bonds in the form of $\mathrm{sp}^{3}-\mathrm{CH}$ and $\mathrm{sp}^{3}-\mathrm{CH}_{2}$, while the two smaller shoulder peaks at $2955 \mathrm{~cm}^{-1}$ and $2855 \mathrm{~cm}^{-1}$ correspond to $\mathrm{sp}^{3}-\mathrm{CH}_{3}$ asymmetric stretching mode and $\mathrm{sp}^{3}$ $\mathrm{CH}_{3}$ symmetric model, respectively $[19,20]$. This suggests that most of the hydrogen atoms in the deposited films are bonded to the $\mathrm{sp}^{3}$-hybridized $\mathrm{C}$ atoms.

\section{Conclusion}

Nanocomposite Ti-Al-C films were deposited by FCVA at different $\mathrm{CH}_{4}$ flows. Two groups of deposited films can be distinguished depending on the composition and microstructure. At low $\mathrm{CH}_{4}$ flow of $30 \mathrm{sccm}$, the microstructure of the films is $\mathrm{TiC}$ dominant $\mathrm{TiC}-\mathrm{C}$ film structure. While the $\mathrm{CH}_{4}$ flow 


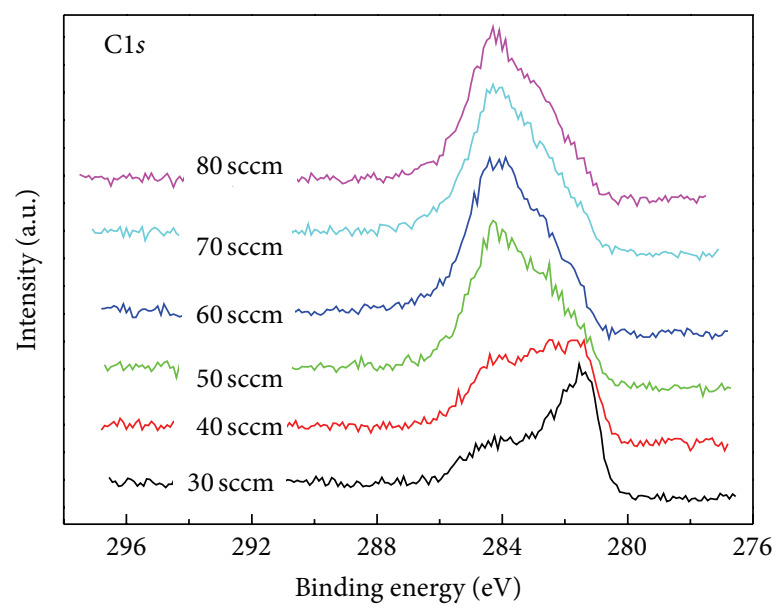

(a)

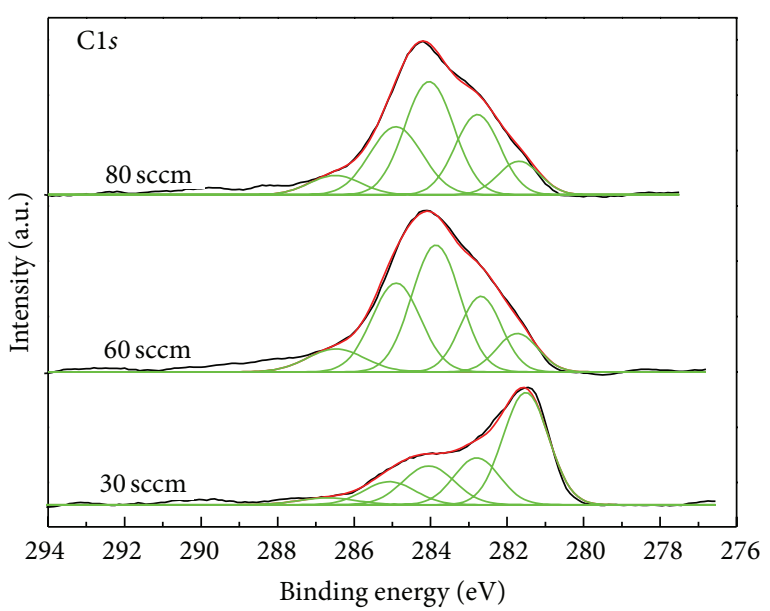

(b)

FIGURE 4: XPS C1s spectra of the films prepared at different $\mathrm{CH}_{4}$ flow.

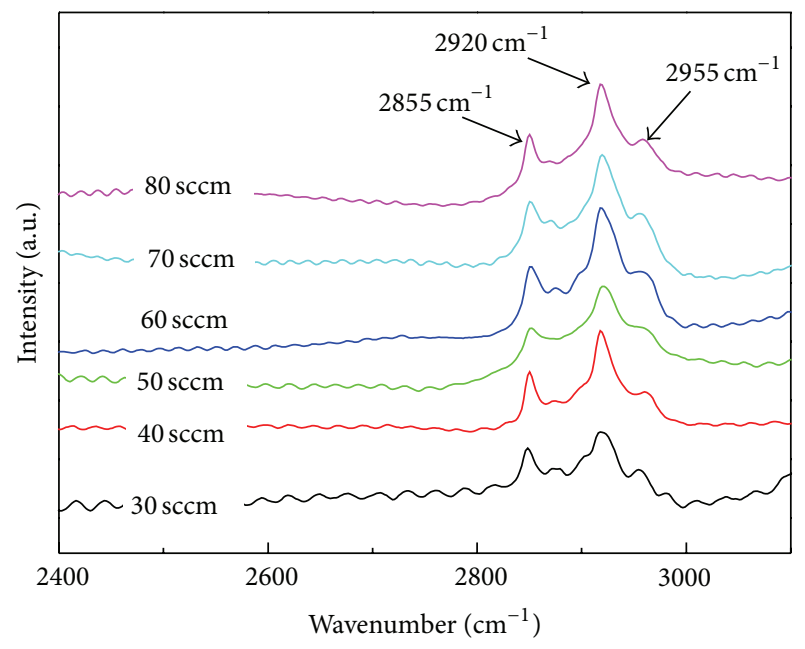

FIGURE 5: IR spectra of the films deposited at different methane flows.

increases to $80 \mathrm{sccm}$, the microstructure of deposited films changes to carbon network dominant TiAl-doped a-C film structure. The XPS and Raman results show the structural change at the $\mathrm{CH}_{4}$ flow increasing up to $50 \mathrm{sccm}$ and higher flows. All the composition and microstructure change can be explained by considering the plasma conditions and the effect of $\mathrm{CH}_{4}$ flow. During the films deposition, as the $\mathrm{CH}_{4}$ flow increased, there is poisoning effect. When the poisoning effect and the plasma emission from the arc spots approach equilibrium, the arc plasma beam will be stable and the composition of the films will change slightly.

\section{Conflict of Interests}

The authors declare that they have no competing interests regarding the publication of this paper.

\section{Acknowledgments}

The authors gratefully acknowledge the Natural Science Foundation of China (Grant no. 50902133), the Project of the Education Department of Henan Province (14A430009), the Open Fund of State Key Laboratory of Solid Lubrication (1201), and the Fund of Henan University of Science and Technology (2013QN001).

\section{References}

[1] M. Stüber, H. Leiste, S. Ulrich, H. Holleck, and D. Schild, "Microstructure and properties of low friction TiC-C nanocomposite coatings deposited by magnetron sputtering," Surface and Coatings Technology, vol. 150, no. 2-3, pp. 218-226, 2002.

[2] B. Yang, Z. H. Huang, H. T. Gao, X. J. Fan, and D. J. Fu, "Dropletfree $\mathrm{TiC}$ nanocrystal-containing diamond-like carbon coatings deposited by combined cathodic arc MF magnetron sputtering," Surface and Coatings Technology, vol. 201, no. 15, pp. 6808-6811, 2007.

[3] J. Robertson, "Diamond-like amorphous carbon," Materials Science and Engineering R: Reports, vol. 37, no. 4-6, pp. 129-281, 2002.

[4] I. Ahmad, S. S. Roy, M. A. Rahman, T. I. T. Okpalugo, P. D. Maguire, and J. A. McLaughlin, "Substrate effects on the microstructure of hydrogenated amorphous carbon films," Current Applied Physics, vol. 9, no. 5, pp. 937-942, 2009.

[5] X. Pang, L. Shi, P. Wang, Y. Xia, and W. Liu, "Effects of Al incorporation on the mechanical and tribological properties of Ti-doped a-C: $\mathrm{H}$ films deposited by magnetron sputtering," Current Applied Physics, vol. 11, no. 3, pp. 771-775, 2011.

[6] J. L. Jiang, Q. Wang, H. Huang, Y. B. Wang, X. Zhang, and J. Y. Hao, "Microstructure and property changes induced by substrate rotation in titanium/silicon dual-doped a-C:H films deposited by mid-frequency magnetron sputtering," Surface and Coatings Technology, vol. 240, pp. 419-424, 2014.

[7] J. L. Jiang, H. Huang, Q. Wang, W. J. Zhu, J. Y. Hao, and W. M. Liu, "Comparative study on structure and properties of titanium/silicon mono- and co-doped amorphous carbon films 
deposited by mid-frequency magnetron sputtering," Surface and Interface Analysis, vol. 46, no. 3, pp. 139-144, 2014.

[8] A.-Y. Wang, K.-R. Lee, J.-P. Ahn, and J. H. Han, "Structure and mechanical properties of $\mathrm{W}$ incorporated diamond-like carbon films prepared by a hybrid ion beam deposition technique," Carbon, vol. 44, no. 9, pp. 1826-1832, 2006.

[9] X.-Z. Ding, B. K. Tay, H. S. Tan, S. P. Lau, W. Y. Cheung, and S. P. Wong, "Preferential orientation of titanium carbide films deposited by a filtered cathodic vacuum arc technique," Surface and Coatings Technology, vol. 138, no. 2-3, pp. 301-306, 2001.

[10] Y. H. Cheng, B. K. Tay, S. P. Lau, and X. Shi, "Influence of substrate bias on the structure and mechanical properties of taC: W films deposited by filtered cathodic vacuum arc," Surface and Coatings Technology, vol. 146-147, pp. 398-404, 2001.

[11] Y. H. Wang, X. Zhang, X. Y. Wu, H. Zhang, and X. Zhang, "Compositional, structural and mechanical characteristics of nc-TiC/a-C:H nanocomposite films," Applied Surface Science, vol. 255, no. 5, pp. 1801-1805, 2008.

[12] Y. H. Wang, X. Zhang, X. Y. Wu, H. Zhang, and X. Zhang, "Effect of filter coil current on properties of nc-TiC/a-C:H nanocomposite film prepared by dual plasma technique," Surface Review and Letters, vol. 14, no. 6, pp. 1143-1148, 2007.

[13] H. L. Wang, S. Zhang, Y. B. Li, and D. Sun, "Bias effect on microstructure and mechanical properties of magnetron sputtered nanocrystalline titanium carbide thin films," Thin Solid Films, vol. 516, no. 16, pp. 5419-5423, 2008.

[14] E. Lewin, E. Olsson, B. André et al., "Industrialisation study of nanocomposite ncTiC/a-C coatings for electrical contact applications," Plasma Processes and Polymers, vol. 6, no. 1, pp. S928-S934, 2009.

[15] H.-X. Liu, X.-F. Wang, L.-P. Wang, and B.-Y. Tang, "Rolling contact fatigue and mechanical properties of titanium carbide film synthesized on bearing steel surface," Surface and Coatings Technology, vol. 201, no. 15, pp. 6606-6610, 2007.

[16] C. Corbella, E. Pascual, G. Oncins, C. Canal, J. L. Andújar, and E. Bertran, "Composition and morphology of metal-containing diamond-like carbon films obtained by reactive magnetron sputtering," Thin Solid Films, vol. 482, no. 1-2, pp. 293-298, 2005.

[17] J. Soldán and J. Musil, "Structure and mechanical properties of DC magnetron sputtered TiC/Cu films," Vacuum, vol. 81, no. 4, pp. 531-538, 2006.

[18] D. E. Wolfe and J. Singh, "Titanium carbide coatings deposited by reactive ion beam-assisted, electron beam-physical vapor deposition," Surface and Coatings Technology, vol. 124, no. 2-3, pp. 142-153, 2000.

[19] H. X. Li, T. Xu, J. M. Chen, H. Zhou, and H. Liu, "Preparation and characterization of hydrogenated diamond-like carbon films in a dual DC-RF plasma system," Journal of Physics D: Applied Physics, vol. 36, no. 24, pp. 3183-3190, 2003.

[20] P. Wang, X. Wang, Y. M. Chen, G. Zhang, W. Liu, and J. Zhang, "The effect of applied negative bias voltage on the structure of Ti-doped a-C:H films deposited by FCVA," Applied Surface Science, vol. 253, no. 7, pp. 3722-3726, 2007. 

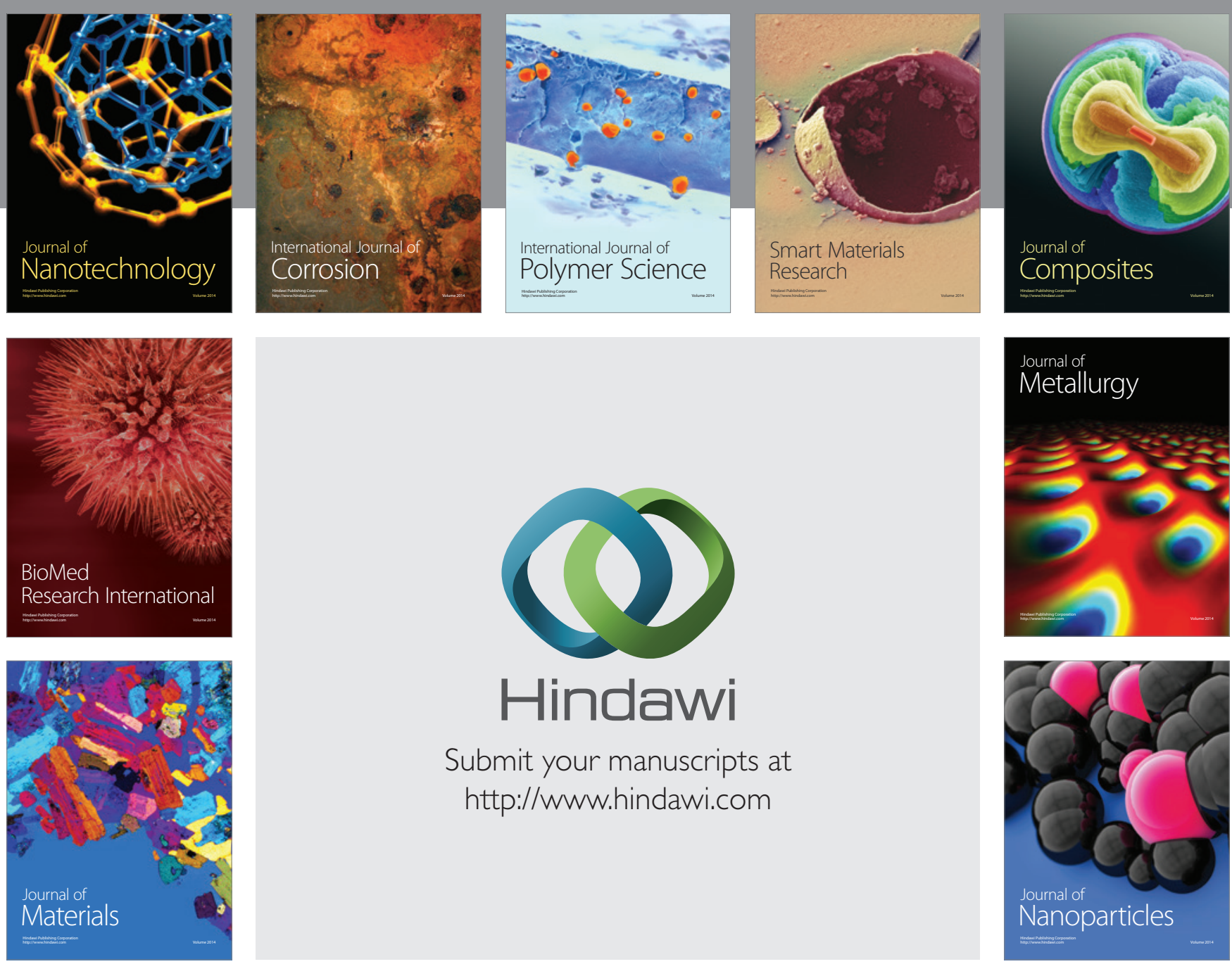

Submit your manuscripts at http://www.hindawi.com
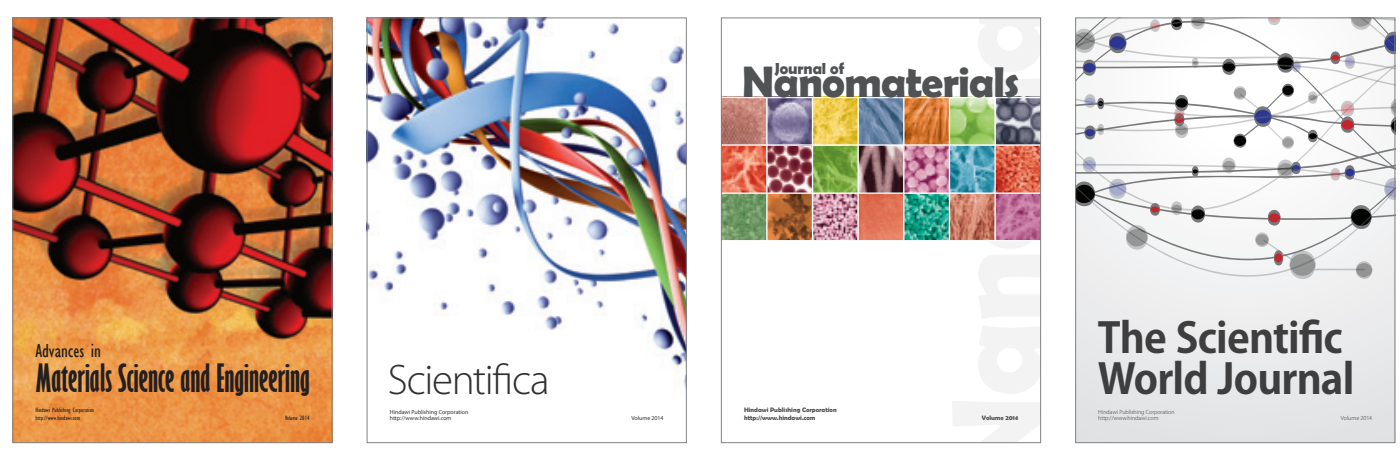

\section{The Scientific World Journal}
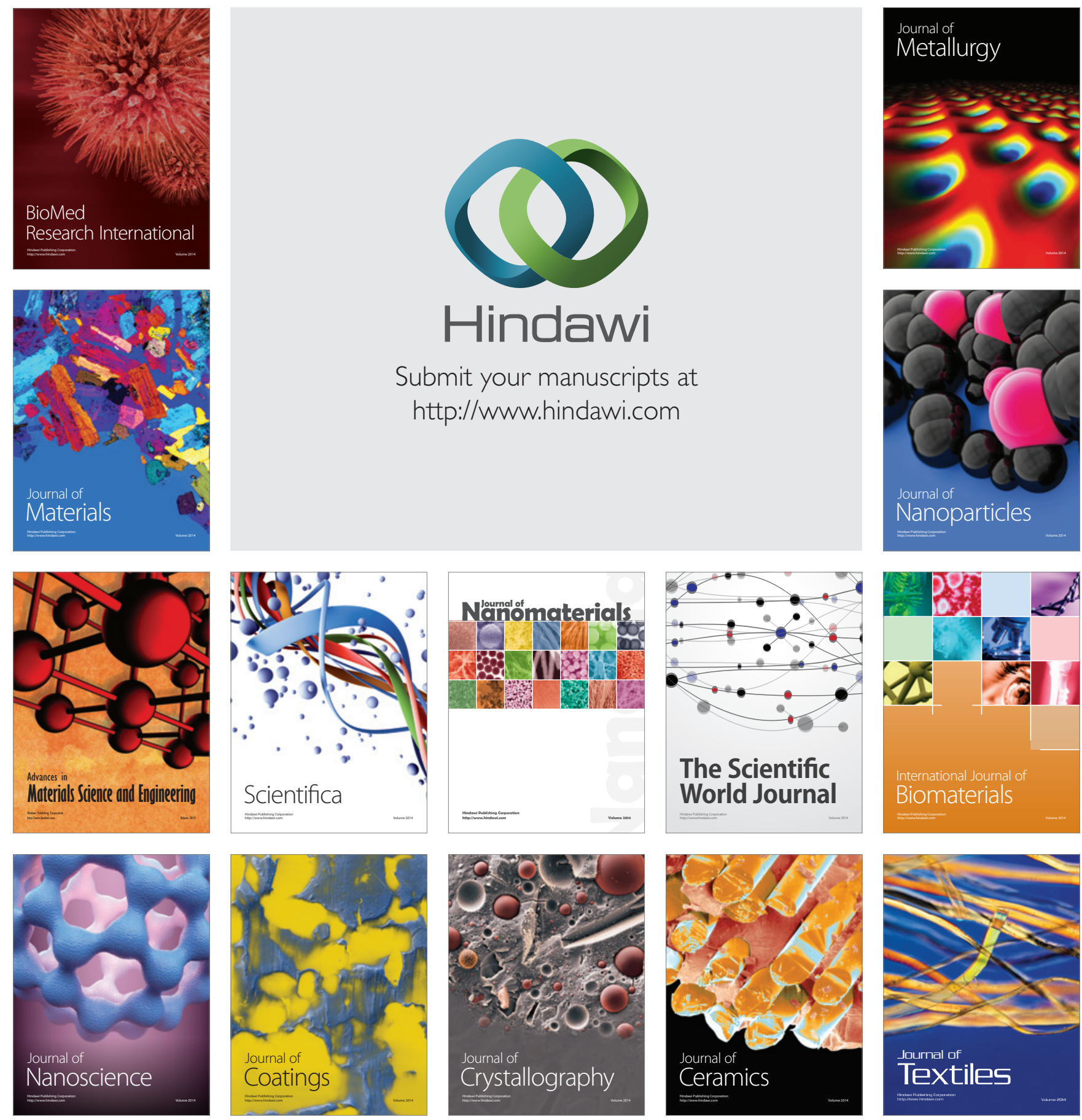